\title{
Fenugreek seed poultice versus cold cabbage leaves compresses for relieving breast engorgement: An interventional comparative study
}

\author{
Hanan Elzeblawy Hassan*1, Eman Ali Abd El Moaty Sheha², Sharbat Thabet Hassanine' ${ }^{2}$, Wafaa Mostafa Ahmed \\ Gamel $^{3}$ \\ ${ }^{1}$ Maternal and Newborn Health Nursing department, Faculty of Nursing, Beni-Suef University, Egypt \\ ${ }^{2}$ Community Health Nursing, Faculty of Nursing, Fayoum University, Egypt \\ ${ }^{3}$ Maternal and Neonatal Health Nursing, Faculty of Nursing, Fayoum University, Egypt
}

Received: September 25, 2019

DOI: $10.5430 /$ jnep.v10n5p82

\begin{abstract}
Accepted: January 10, 2020
Online Published: February 26, 2020
\end{abstract}

URL: https://doi.org/10.5430/jnep.v10n5p82

\begin{abstract}
Background: Breast engorgement is an uncomfortable and painful condition affecting a large slid of mothers in their early postpartum period. Several approaches have been explored for pharmacological or non-pharmacological interventions applied to the treatment of breast engorgement. Some of the non-medical interventions include Fenugreek seed poultice and cold cabbage leaves compresses. Aim: Study the impact of nursing intervention on relieves of breast engorgement among puerperal breastfeeding women and compare Fenugreek seed poultice versus could cabbage leaves compresses as two different nursing care approaches of on relieving of breast-engorgement.

Methods: Setting: Postnatal unit and outpatient clinic of Beni-Suef and El-Fayoum University Hospital. Design: A quasiexperimental comparative study. Subjects: A purposive sample of a total of 100 puerperal mothers; 50 in the Fenugreek group \& 50 in the cold Cabbage group. Tools: A specialized designed structured interview schedule and Breast Engorgement Assessment Scale (Numerical rating scale, Modified Reeda Scale, Six-points engorgement scale, Fever Chart, and LATCH breastfeeding charting scale).

Results: A significant improvement of breast condition after intervention for both groups regardless of the applied measure was found; however, the improvement was better and shorter time among Fenugreek group than Cabbage group $(p<.05)$.

Conclusions: For the management of breast engorgement, both Fenugreek seed poultice and cold Cabbage leaves were effective. However, Fenugreek seed was more highly effective where breast engorgement was alleviated in a shorter time than cold Cabbage leaves. Recommendations: Further randomized controlled trials with possible placebo treatment should be carried out to elucidate the non-specific effects of Fenugreek seed poultice and cold Cabbage leaves application.
\end{abstract}

Key Words: Breast-engorgement, Nursing intervention, Fenugreek seed poultice, Cabbage leaves compresses

\section{INTRODUCTION}

Breast engorgement is an uncomfortable, unpleasant, and painful condition that affects a number of women in their early postpartum period. ${ }^{[1]}$ Considered to be one of the most common causes of morbidity affecting early motherhood and early puerperium functions and experience. ${ }^{[2]}$ Breast en-

\footnotetext{
*Correspondence: Hanan Elzeblawy Hassan; Email: nona_nano_1712@yahoo.com; Address: Maternal and Newborn Health Nursing Department, Faculty of Nursing, Beni-Suef University, Egypt.
} 
gorgement is a common physiological problem for lactating women that is triggered by a rat of secretion which exceeds the rate of milk ejection, and/or poor/shallow latching from the infant. The reported incidence of breast engorgement ranged from $20.0 \%$ to $77.0 \%$ between studies. ${ }^{[1,3]}$

The precipitating factors of breast engorgement include the missing baby early, weak latch, baby formula supplementation, unsuccessful/inadequate breastfeeds, improper feeding cues, lymphatic and vascular congestion, the use of a breast pump without medical/clinical indication and interstitial edema for the first two weeks after birth. ${ }^{[4,5]}$ Breastencouragement can interfere with breastfeeding, leading to early cessation of breastfeeding and associated with a severe breast infection. Breast engorgement can cause pain and insufficient emptying of milk during lactation. ${ }^{[1,3,6]}$

Breast engorgement, in turn, can cause numerous consequences as swelled and painful breasts combined with a sudden increase in the amount of milk, vascular and lymphatic congestion/obstruction contributing to interstitial edema. Previous studies have indicated reported that; poor management of breast-engorgement may lead to failure of milk production in the early postpartum period; leading to early cessation of breastfeeding (Breast-engorgement is a painful issue that may lead to premature weaning). The main reason for the early cessation of breastfeeding is due to the pain caused by engorgement. If this condition isn't handled effectively, mastitis/breast abscess may be noticed. ${ }^{[1,5,7]}$

Through their professional practice, nurses contribute to the health and well-being of mothers, babies, and families by facilitating qualified and competent treatment in the clinical management of breastfeeding. They should also direct, illustrate techniques, and demonstrate maneuvers to express milk to mothers; so that they can practice while feeding their babies and avoid breast engorgement from occurring. ${ }^{[6]}$

The main aim of management of breast-engorgement is to attain, sustain, and maintain of breast-milk flow, successfully, and empty the breast-milk, effectively, through the baby and/or expression to avoid engorgement. The current approach involves a combination of pharmacological (pain medications) and non-pharmacological measures. Intervention toward the goal of alleviating or relieving patient pain and other discomforts related to engorgement. Concerning pain, some women choose not to use medications at all or to use it infrequently for various reasons, therefore, alternative methods to relieve these discomforts need to be available to such women. Over the years, numerous strategies for the treatment of this problem have been employed such as kangaroo care, direct massage to the areas with blocked ducts, fluid limitation, cold cabbage leaves, binding the breasts or wearing a tight brassiere, cold gel packs; cabbage leaves extract, cold compresses, guasha as a form of Chinese massage, acupuncture, and therapeutic ultrasound. ${ }^{[3,5]}$

The present study was conducted to compare the compresses of Fenugreek seed versus cold cabbage leaves as two different non-pharmacological approaches to breast engorgement relief. The research illustrates the need to strengthen mothers learning as well as highlight the degree to which they have breastfeeding awareness and practices. This helps in healthy and safe breastfeeding and prevents engorgement. Non-pharmacological interventions are becoming increasingly popular for breast engorgement. The use of cabbage leaves is one of the common non-pharmacological interventions used in mammalian breast engorgement; it reduces the tenderness, pain, and swelling of breasts. ${ }^{[3,5]}$ Also, Fenugreek herb has been known to help reduce enlarged breasts ant used traditionally for engorged breast. ${ }^{[8]}$

Fenugreek (Trigonella foenum-gráecum), a plant that belongs to the Fabaceae family, is widely distributed throughout the world. In this context, fenugreek, an annual legume, is extensively cultivated in most regions of the world for its medicinal value. ${ }^{[9]}$

From very early times, fenugreek seeds were known and valued as medicinal material. The seeds are known to be of commercial interest to the pharmaceutical industry as a source of steroid diosgenin. ${ }^{[10]}$ Fenugreek is now commonly cultivated as a pharmaceutical crop. Mucilaginous seeds are considered to have many medicinal properties, such as tonic, emollient, carminative, demulcent, diuretic, astringent emmenagogue, expectorant, restorative, aphrodisiac and vermifugal properties, and have been used to treat mouth ulcers, chapped lips, and irritation of the stomach. In various countries around the world, fenugreek leaves and seeds are used for various purposes, such as medicinal as anti-cancer and anti-microbial, food-producing (rice stew in Iran, flavor cheese in Switzerland, syrup and bitter running in Germany, mixed seed powder with flour to make flatbread in Egypt, curries, colors, young seedlings eaten as vegetables, etc., plants are used in different countries for medicinal purposes and are a source of many powerful and strong drugs. This plant is active in obesity because body fats can be reduced by it. ${ }^{[8]}$ Other traditional uses of fenugreek seeds and leaves as stated in the references; control and treat diabetes, reducing blood sugar, high blood pressure, and cholesterol levels, cough, coughing, congestion, bronchitis, fever, headaches/migraines, flatulence, diarrhea, anemia, irregular menstrual cycles and arthritis, and to relieve menstrual pain and labor pain, and also as an appetite stimulant. Fenugreek was also used to reduce inflammation and dandruff as an internal poultice. ${ }^{[11]}$ 
For breast-engorgement; steep several ounces of fenugreek seeds in a cup of warm water for 15 minutes. Let the seeds cool down and then mash them. Place mashed seeds while still warm on a clean wet cloth and use them on engorged breasts as a poultice or plaster to help with let-down, ejection of milk, and sore spots. Nursing mothers can also get ready teas and tinctures (or drink its fenugreek tea), or soak 1-2 teaspoons of the seeds in water overnight and pour that water of the next day. ${ }^{[11]}$ Fenugreek plant, widely used as a culinary herb and imitating maple syrup flavor, is one of the oldest known medicinal herbs in the world and used as a galactagogue, traditionally, by mothers. Several researchers believed that fenugreek seeds may be estrogenic, which may stimulate the development of sweat, and since the breast is a modified sweat gland, fenugreek may influence breast milk production in this manner. ${ }^{[12,13]}$

Cabbage (Brassica oleracea) leaves have been applied topically to the breasts to treat breast engorgement. Some researchers cut out a hole in the applied leaves to keep the dryness of the nipple. Leaves should be applied frozen/refrigerated or at room temperature. Various studies and investigators found that; cabbage leaves may have been beneficial for breast engorgement and pain reduction regardless of its temperature. The researchers felt that the intervention was cheap and unlikely to cause harm to mothers; it might be soothing for the lactating woman. ${ }^{[14]}$ Some lowquality evidence indicates that maternal cabbage ingestion might cause colic in their breastfed infants. ${ }^{[15]}$ Additionally, some breastfeeding experts advised that cool cabbage leaves be used to relieve painful breast engorgement. Many women who have tried cabbage leaves claim the treatment beings relief from discomfort and improve milk flow. Since millennia, carbohydrate leaves have been used as a folk remedy for a wide variety of ailments, and over the past 10 years, lactation professionals have generated much-renewed interest. ${ }^{[1]}$

Rosier \& Fraser and Cooper, as well, reported anecdotally the use of chilled cabbage leaves applied to engorged breasts and modified in a small sample of women every two hours as having a rapid effect on edema reduction and increased flow. Cabbage leaves are favored by mothers; the advantage of using cabbage leaves in contrast with other health regimens is its low cost and convenience. The cool promotes pain relief by decreasing the excitability of the nerve ending, decreasing nerve conduction local vasoconstriction with reduces edema, decrease muscle irritability and spasm. ${ }^{[16,17]}$

Non-pharmacological approaches were used in the study hospital to treat mother's breast-engorgement; a systematic review on the efficacy of the application of cabbage leaf on pain and hardness in breast-engorgement and its effect on breastfeeding period was performed. ${ }^{[18]}$ The review found that cabbage leaves can potentially help minimize breast pain and hardness and improve breastfeeding duration. ${ }^{[3,5]}$ The leaves of cabbage contain enzymes such as irregular rapine and have proved to be a good source of antioxidants. ${ }^{[5,19]}$ The Heteroside and sulfur compound in cabbage leaves is antiseptic, disinfectant, anti-bacterial, which helps to relieve pain and swelling, and helps to reduce tissue congestion in mild, moderate and severe discomfort due to dilatory local capillaries. ${ }^{[1,3,5]}$ Cabbage has antioxidant, anti-irritant and anti-inflammatory properties; this is why lactation consultants also prescribe green cabbage leaf compresses to reduce swelling in moderate to severe engorgement. ${ }^{[6]}$

\subsection{Significant of the study}

Breast engorgement is considered among the most significant problems encountered in the first weeks of motherhood. Moderate to severe engorgement is of more concern. Rates of engorgement, as have been reported in the literature based on numerous definitions, is $20.0 \%$ to $85.0 \%$. It is one of the most common minor discomforts confronting nursing women 2-4 days after delivery, especially primiparae. The main importance lies in the fact that the engorged breast can prevent nursing, leading to a decrease in milk production. Also, engorgement may be a forerunner of acute non-infective mastitis and breast abscess. ${ }^{[1]}$

Maternity, community health nurses and midwives, as well, play an important role in early detection and proper effective intervention of the engorged breast to protect woman's health and enhance their successful breastfeeding. One of the most important aspects of midwifery care is providing accurate and consistent advice on how to prevent breast-engorgement and, if the problem occurs, how to overcome it to reduce early cessation of breastfeeding.

Although there is a dearth of nursing research regarding the effect of Fenugreek seed poultice and a few studies regarding cold cabbage leaves compresses, as well, on the relief of breast engorgement have been conducted, the findings from these studies were inconclusive. At those studies, breast pain was measured as an index of breast engorgement; however, breast engorgement itself was not measured. Our research was, therefore, conducted to study the effect of nursing intervention on breast engorgement relief among puerperal breastfeeding women and to compare Fenugreek seed poultice versus cold cabbage leaves compresses as two different approaches to breast engorgement relief nursing.

\subsection{Aim of the study}

Investigate the impact of nursing intervention on relieving breast engorgement among puerperal women. The aims of 
this study achieved through:

- Apply deferent measures of nursing intervention for women to relieve the engorgement of the breast; these measures are:

(1) Appling Fenugreek seed poultice (FSP)

(2) Administered compresses of cold cabbage leaves (CCLC); cooled in the freezer for about 20-30 minutes.

- Evaluate the effect of two different nursing measures on relieving of breast engorgement.

- Compare the effect of Fenugreek seed poultice versus cold cabbage leaves on breast engorgement.

\subsection{Research hypothesis}

- Breast engorgement among puerperal women will be relieved after the application of the nursing intervention. The mean of pain, tenderness, edema, redness scores for both groups will be lower than the pre-one scores.

- Fenugreek seed poultice will be more effective in relief breast engorgement (with statistically significant differences) than cold Cabbage leaves over time.

\section{SUBJECTS AND METHODS}

\subsection{Technical design}

\subsubsection{Study design}

This study is an interventional comparative study that is quasi-experimental. A randomized pre/post-intervention twogroup study design has been implemented. For group A (Fenugreek seed poultice) and group B (cold Cabbage leaves application), mothers are randomly assigned.

\subsubsection{Setting}

The study was conducted in the postnatal unit and outpatient clinic of Beni-Suef and El-Fayoum University Hospital.

\subsubsection{Subjects}

Sample type: A purposive sample.

Sample size: 100 postnatal women with breast-engorgement (during the 12 months of data collection period by using time series analysis) were recruited on their 3rd postnatal day and before discharge from the postnatal unit of Beni-Suef and El-Fayoum University Hospital, in Egypt. No limitations were imposed on the parity of the subjects.

\section{Samples' inclusion criteria:}

1) Postnatal mothers with breast-engorgement and willingness to participate in the study.

2) Able to read and write.

3) Free from medical diseases that interfere with breastfeeding (infectious disease as active pulmonary tuberculosis).
4) Her baby is normal.

5) Breastfed woman that experienced breast-engorgement within 14 days-postpartum.

6) Fulfilled 5 out of 10 criteria using an evaluation method for infant breastfeeding (LATCH score).

\section{Samples' exclusion criteria:}

1) Women who are taking lactation suppressant.

2) Women who didn't breastfeed their babies.

3) Women who have medical conditions that caused pain or fever (e.g. wound infection, breast infection, upper respiratory tract infection "URTI", or urinary tract infection "UTI") as known from their medical records.

\section{Sample technique:}

Participated women were equally allocated randomly into two intervention groups; group A and group B.

A-Group A: This group comprised half of the mothers (50 women) who suffer from breast engorgement. They were trained to apply Fenugreek seed poultice (FSP) to relief engorgement.

$B$-Group B: This group was comprised of the other half the mothers (50 women) who suffer from breast engorgement and they were trained to apply cold Cabbage leaves application (CCLC) to relief engorgement.

\subsubsection{Tools of data collection}

Two tools were used to collect the necessary data from the study subjects as the following:

\section{Tool (1): A specialized designed structured interview schedule}

It was developed based on the review of currently related literature and used by the researchers to collect the necessary data about the study subjects. It included the participants' sociodemographic data and their general characteristics (name, age, residence, address, phone number, educational level, type of family, family income, occupation) as well as clinical data (date/mode of delivery, type/amount/frequency of medications used after delivery) were obtained after receiving a consent from the participanting women.

Tool (2): Breast Engorgement Assessment Scale (BEAS): This tool was specially designed to provide the baseline data of the subjects regarding their signs and symptoms of the engorged breast. The outcomes assessed included the primary outcome of pain severity, and secondary outcomes of redness, breast hardness, body temperature, and charting scale for breastfeeding (LATCH). Furthermore, follow-up checklist to evaluate the efficacy of nursing methods and to compare the application of Fenugreek seed poultice versus cold Cabbage leaves, as well, used to relieve the breast engorgement among the two groups to identify the degree of 
improvement after applying the suggested methods of treatment for breast engorgement. This tool comprised five main parts:

Part (A): Numerical rating scale (NRS). ${ }^{[20-22]}$

Numerical Rating Scale (NRS) consists of a straight horizontal line with two endpoints (the 11-point numeric scale ranges from zero to ten). Zero usually represents one pain extreme 'no pain at all' whereas the upper limit '10' represents the other pain extreme 'the worst pain, imaginable, ever possible. In this study, moderate pain suggested a pain score of 4 to 6 and severe pain indicated 7 to 10 . On the line between the two endpoints, each woman is asked to circle her pain level. The distance between 'no pain at all' and the mark determines the pain of the subject's pain Figure 1.

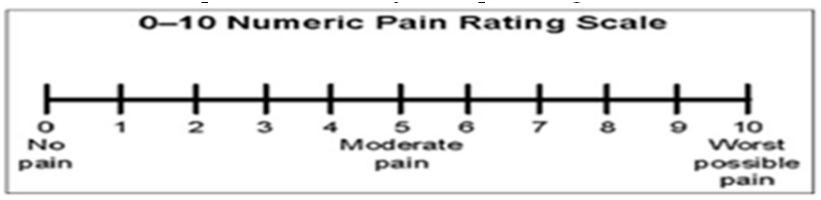

Figure 1. 0-10 numeric pain rating scale

Part (B): Modified Reeda Scale (MRS) ${ }^{[23]}$

The REEDA Scale is a tool used to provide the most effective means for evaluating the condition of the skin in relation to 5 factors (Redness, Edema, Ecchymosis, Discharge, and Approximation "healing").

The modified Reeda Scale (MRS) was used to provide the most objective means for evaluating the condition of the engorged breast after delivery in relation to redness (R). Mild redness was characterized by presence less than $0.25 \mathrm{~cm}$ of redness in the bilateral breasts or less than $0.5 \mathrm{~cm}$ of redness in the unilateral breast. Moderate redness was characterized by an increase of redness to $0.5 \mathrm{~cm}$ in the bilateral breasts or $1 \mathrm{~cm}$ in only one breast. Severe redness was characterized by an increase of redness to more than $0.5 \mathrm{~cm}$ in each breast or more than $1 \mathrm{~cm}$ in only one breast.

Part (C): Six-points engorgement scale (6-PES) ${ }^{[24]}$

The breast-engorgement-assessment-scale (BEAS) was used to evaluate the hardness of the breast. Nikodem et al. (1993) and Roser (1966) developed this scale based on the simple scale of the description used. It was regularly used in the participating hospital to test breast engorgement through the measurement of breast hardness. ${ }^{[25,26]}$ Between 1 and 6, breast-engorgement was graded. Grade " 1 " has meant that the breasts are soft and milk flows freely while grade " 6 " has meant that the breasts are very hard and painful and there is no flow of milk. A score of " 4 " and above is graded as breast engorgement. Postnatal women answer the questions and score as (1) for hard and no breast changes; score as (2) for mild breast changes; score as (3) for the firm and tender breasts; (4) for the firm and beginning breast tenderness, score as (5) for the firm and tender breasts, and score as (6) for very firm and tender.

\section{Part (D): Fever Chart}

Oral clinical thermometers were used to measure mothers' body temperature. Fever was defined if a woman's body temperature was above 37.5 degrees Celsius. In this study, a temperature score of 37 to 37.4 indicated no fever; a temperature score of 37.5 to 37.9 indicated mild fever; a temperature score of 38 to 38.4 indicated moderate fever and 38.5 to above indicated severe fever.

Part (E): LATCH breastfeeding charting scale. ${ }^{[27]}$

LATCH breastfeeding charting scale was created by Jensen et al in 1994. It is based on the method of Apgar scoring. This system assigns a numerical score $(0,1$, or 2$)$ to 5 keys of breastfeeding components that identified by the letters of the acronym LATCH: "L" referred to how well the infant latches onto the breast, "A" referred to the amount of audible swallowing observed, "T" referred to mother's nipple condition/type, " $\mathrm{C}$ " referred to mother's level of comfort, and " $\mathrm{H}$ " referred to the amount of assistance that the mother needs to hold her infant to the breast. The total score is ranged from zero to ten; a higher score will represent a successful breastfeeding. ${ }^{[27]}$

\subsection{Operational design}

The study, to be completed, was passed through different phases as follows: Preparatory phase then the pilot study and the fieldwork.

\subsubsection{Preparatory phase}

Tools development: The tools of data collection were developed by the researchers after an extensive review of recent and related literature.

\subsubsection{Ethical considerations}

Researchers took consent from women included to participate in the study. The researchers' tools didn't embarrass of modesty and didn't cause any harm or pain for the participant women. The researchers' tools didn't cause any physical, psychological and social risk. The participants have the right to withdraw at any time.

\subsubsection{Pilot study}

A pilot study was carried out on $10 \%$ of women (10 cases) who were excluded from the sample to ascertain their clarity, estimated time, efficiency and applicability and the necessary changes were undertaken. 


\begin{tabular}{|c|c|c|c|}
\hline \multicolumn{4}{|c|}{ LATCH scoring table } \\
\hline & 0 & 1 & 2 \\
\hline $\begin{array}{c}\text { L } \\
\text { Latch }\end{array}$ & $\begin{array}{l}\text { - Too sleepy or reluctant } \\
\text { - No latch achieved }\end{array}$ & $\begin{array}{l}\text { - Repeated attempts } \\
\text { - Hold nipple in mouth } \\
\text { - Stimulate to suck }\end{array}$ & $\begin{array}{l}\text { - Grasps breast } \\
\text { - Tongue down } \\
\text { - Lips flanged } \\
\text { - Rhythmic sucking }\end{array}$ \\
\hline $\begin{array}{l}\text { A } \\
\text { Audible } \\
\text { sound }\end{array}$ & - Non & - A few with stimulation & $\begin{array}{l}\text { - Spontaneous \& } \\
\text { intermittent }>24 \text { hours old } \\
\text { - Spontaneous \& frequent } \\
<24 \text { hours old }\end{array}$ \\
\hline $\begin{array}{c}\text { T } \\
\text { Type of nipple }\end{array}$ & - Inverted & - Flat & $\begin{array}{l}\text { - Diverted (after } \\
\text { stimulation) }\end{array}$ \\
\hline $\begin{array}{c}\text { C } \\
\text { Comfort } \\
\text { (breast nipple) }\end{array}$ & $\begin{array}{l}\text { - Engorgement } \\
\text { - Cracked, bleeding, large } \\
\text { blisters or bruises } \\
\text { - Sever discomfort }\end{array}$ & $\begin{array}{l}\text { - Filling } \\
\text { - Reddened } \\
\text { - Small blisters or bruises } \\
\text { - Mild/moderate discomfort }\end{array}$ & $\begin{array}{l}\text { - Soft } \\
\text { - No tender }\end{array}$ \\
\hline $\begin{array}{c}\text { H } \\
\text { Hold } \\
\text { (positioning) }\end{array}$ & $\begin{array}{l}\text { - Full assist (staff hold } \\
\text { infant at the breast) }\end{array}$ & $\begin{array}{l}\text { - Minimal assist (e.g. elevate } \\
\text { head of bed, place pillows } \\
\text { for support). } \\
\text { - Teach one side; mother } \\
\text { does other } \\
\text { - Staff holds and then mother } \\
\text { takes over }\end{array}$ & $\begin{array}{l}\text { - No assistant from staff } \\
\text { - Mother able to position } \\
\text { and hold infant }\end{array}$ \\
\hline
\end{tabular}

Figure 2. LATCH scoring table

\subsubsection{Field Work (Procedure)}

The researchers select lactating mothers who fulfilled the inclusion criteria. The researchers explained the aim of their study to every woman, and then her consent to participate in the study was obtained. Each interview was conducted individually and in a total privacy to assure that information to be obtained will be confidential and will be used only for research purpose. Three days per week specified for data collection until the study sample completed over a period of 12 months starting from the beginning of August 2018 till July 2019. Women attended to the postnatal ward or outpatient clinic were interviewed. The average number of the interviewee was 1-4 per day and the time taken for each sheet to complete was 60-75 minutes, depending upon the response of the interviewee. The study proceeds as the following:

A. The whole sample (100 lactating women) that was actually suffered from breast engorgement. They were interviewed by the researchers in the 3rd postnatal day to find out general characteristics. In addition, the condition of their breasts was assessed during the initial interview which is used Breast Engorgement Assessment Scale (BEAS) to identify their current signs, symptoms and complain (base-line data of the participants).

B. Block randomization created randomly by a biostatistician was used to assign eligible mothers who consented to participate in the following groups via sequentially numbered opaque sealed envelopes: group A (Fenugreek seed poultice), and group B (cold Cabbage leaves application).

Group (A): Fenugreek seed poultice (FSP): In this group, mothers instructed to steep several ounces of fenugreek seeds in a cup or so of water. Let seeds cool, and then mash them. Place on a clean warm tissue cloth, and use it as a poultice or plaster on the engorged breast to help with let-down and sore spots.

Group (B): Cold Cabbage leaves application (CCL): Cold cabbage leaves were applied by mothers in this group on both breasts. The cabbage leaves should be from common green cabbages. Cold leaves, which were refrigerated for about twenty to thirty minutes in the freezer, were placed for 30 minutes inside the brassier of women. The researcher also instructed the mother about:

- Whether to leave the compress until the leaves get witted (about 20-30 minutes)?

- Not to reuse the plants' leaves.

- Repeat application of cabbage leaves compresses three or four times (approximately every 4 to 6 hours) per 24 hours.

- After each feeding, put fresh cabbage leaves and leave until the next feed.

- Using cold cabbage leaves until engorgement subsides.

\subsubsection{Follow up}

In this phase, reassessment of women's breast condition, using the same tools which were used in the 1st visit, was done for the two groups. Pain, hardness, and temperature data, symptoms of breast engorgement, pain, and LATCH were collected at four times after baseline (pre-intervention); 12-hour, 24-hour, 36-hour, and 48-hour nursing application. 
Throughout the study duration, the researchers follow up the participated mothers who were discharged from the hospital via mobile phone or home visit.

\subsection{Administrative design}

Official approval was received from appropriate authorities to perform the research following clarification of the study's intent.

\subsection{Statistical design}

The collected data have been computerized, revised, categorized, classified, tabulated, analyzed, and presented in a concise descriptive and associated statistical form using version 20 of the SPSS statistical software. Then appropriate tables were prepared by used statistical formulas. The following statistical measures were used:

A. Descriptive measures included percentages, arithmetic mean $(\bar{x}$, and standard deviation (SD).

B. Statistical tests included:
(1) Chi-square $\left(\chi^{2}\right)$ test for analysis of qualitative variables to comparing two or more types of data where all categorical.

(2) $T$-test for qualitative variables analysis to comparing continuous vs. two categories.

C. Graphical presentation contained Bar-chart diagrams.

D. The significance point ( $p$ value) chosen for this analysis was .05 or less.

\section{RESUltS}

The study sample included 100 postnatal women with the mean age of the Fenugreek group was $24.14 \pm 5.99$ years old, and for Cabbage group was $23.22 \pm 10.49$ years old, respectively. There was no significant difference in the all item of the participants' socio-demographic and general characteristics of age, education, occupation, and family income which displayed homogeneity of the two groups (see Table 1).

Table 1. Comparison of the participants' socio-demographic and general characteristics among two groups

\begin{tabular}{|c|c|c|c|c|c|c|}
\hline \multirow{3}{*}{ Variables } & \multicolumn{4}{|c|}{ Study groups } & \multirow{3}{*}{$\begin{array}{l}T \& \chi^{2} \\
\text { Test }\end{array}$} & \multirow{3}{*}{$p$-value } \\
\hline & \multicolumn{2}{|c|}{$\begin{array}{l}\text { Fenugreek Group } \\
(\mathrm{n}=\mathbf{5 0})\end{array}$} & \multicolumn{2}{|c|}{$\begin{array}{l}\text { Cabbage Group } \\
(n=50)\end{array}$} & & \\
\hline & $\mathbf{N}$ & $\%$ & $\mathbf{N}$ & $\%$ & & \\
\hline \multicolumn{7}{|l|}{ Age (in years) } \\
\hline$<20$ & 19 & 38.0 & 17 & 34.0 & & \\
\hline $20-<30$ & 22 & 44.0 & 30 & 60.0 & $T=1.07$ & $p>.05$ \\
\hline$\geq 30$ & 9 & 18.0 & 3 & 6.0 & & \\
\hline Mean $\bar{x} \pm \mathrm{SD}$ & \multicolumn{2}{|c|}{$24.14 \pm 5.99$} & \multicolumn{2}{|c|}{$23.22 \pm 10.49$} & & \\
\hline \multicolumn{7}{|l|}{ Education } \\
\hline Basic education & 4 & 8.0 & 7 & 14.0 & \multirow{4}{*}{$\chi^{2}=3.0$} & \multirow{4}{*}{$p>.05$} \\
\hline Secondary equivalent education & 15 & 30.0 & 19 & 38.0 & & \\
\hline Graduate education & 22 & 44.0 & 14 & 28.0 & & \\
\hline Post graduate education & 9 & 18.0 & 10 & 20.0 & & \\
\hline \multicolumn{7}{|l|}{ Job } \\
\hline Yes & 13 & 26.0 & 9 & 18.0 & \multirow[t]{2}{*}{$\chi^{2}=0.9$} & \multirow[t]{2}{*}{$p>.05$} \\
\hline No & 37 & 74.0 & 41 & 82.0 & & \\
\hline \multicolumn{7}{|l|}{ Family Income } \\
\hline Unsatisfied & 29 & 58.0 & 23 & 46.0 & \multirow{3}{*}{$\chi^{2}=2.1$} & \multirow{3}{*}{$p>.05$} \\
\hline Just enough & 17 & 34.0 & 23 & 46.0 & & \\
\hline Satisfy and can save & 4 & 8.0 & 4 & 8.0 & & \\
\hline
\end{tabular}

Table 2 reveals that most of the studied sample of Fenugreek group and Cabbage group $(78.0 \% \& 88.0 \%)$, respectively, were delivered normally, the remaining of them had a cesarean section within 4 to 7 days postpartum with the mean
$(4.97 \pm 2.77 \& 4.89 \pm 2.42)$. The majority of them delivered a full term $(98.0 \%$ \& $100.0 \%)$, single fetus $(86.0 \%$, $88.0 \%)$; moreover, the majority of them; $(90.0 \% \& 94.0 \%)$ their babies were rooming in with them, most of them $(64.0 \%$ 
\& $58.0 \%$ ) had exclusive breastfeeding. More than half of the mothers $(58.0 \%$ \& $68.0 \%)$ had a normal nipple. There was no significant difference between two groups (Fenugreek group \& Cabbage group, respectively) in the item of the participants' breastfeeding and newborns' characteristics (parity, number of delivered fetuses, gestational age, exclusive breastfeeding, type of nipple, medication used for pain relief and postnatal days) which displayed homogeneity of the two groups.

Table 2. Comparison of the participants' obstetrical history, breastfeeding and newborns' characteristics among two groups

\begin{tabular}{|c|c|c|c|c|c|c|}
\hline \multirow{3}{*}{ Variables } & \multicolumn{4}{|c|}{ Study groups } & \multirow{3}{*}{$\chi^{2} \& t$ Test } & \multirow{3}{*}{$p$-value } \\
\hline & \multicolumn{2}{|c|}{$\begin{array}{l}\text { Fenugreek Group } \\
(\mathrm{n}=\mathbf{5 0})\end{array}$} & \multicolumn{2}{|c|}{$\begin{array}{l}\text { Cabbage Group } \\
(n=50)\end{array}$} & & \\
\hline & $\mathbf{N}$ & $\%$ & $\mathbf{N}$ & $\%$ & & \\
\hline \multicolumn{7}{|l|}{ Parity } \\
\hline Multiparous & 18 & 36.0 & 14 & 28.0 & \multirow{3}{*}{$\chi^{2}=0.7$} & \multirow{3}{*}{$>0.5$} \\
\hline Primiparous & 32 & 64.0 & 36 & 72.0 & & \\
\hline Mean $\bar{x} \pm \mathrm{SD}$ & \multicolumn{2}{|c|}{$18 \pm 0.8$} & \multicolumn{2}{|c|}{$1.3 \pm 2.3$} & & \\
\hline \multicolumn{5}{|l|}{ Mode of delivery } & \multirow{3}{*}{$\chi^{2}=3.8^{*}$} & \multirow{3}{*}{$p \leq .05$} \\
\hline Caesarian Section (C.S) & 11 & 22.0 & 6 & 12.0 & & \\
\hline Normal Vaginal Delivery (NVD) & 39 & 78.0 & 44 & 88.0 & & \\
\hline \multicolumn{5}{|l|}{ Fetus } & \multirow{3}{*}{$\chi^{2}=0.88$} & \multirow{3}{*}{$p>.05$} \\
\hline Twin & 7 & 14.0 & 6 & 12.0 & & \\
\hline Single & 43 & 86.0 & 44 & 88.0 & & \\
\hline \multicolumn{5}{|l|}{ Gestational age } & \multirow{3}{*}{$\chi^{2}=0.69$} & \multirow{3}{*}{$p>.05$} \\
\hline Full term & 49 & 98.0 & 50 & 100 & & \\
\hline Pre-term & 1 & 2.0 & 0.0 & 0.0 & & \\
\hline \multicolumn{5}{|l|}{ Baby room in with mother } & \multirow{3}{*}{$\chi^{2}=3.5^{*}$} & \multirow{3}{*}{$\mathrm{p} \leq .05$} \\
\hline Yes & 45 & 90.0 & 47 & 94.0 & & \\
\hline No & 5 & 10.0 & 3 & 6.0 & & \\
\hline \multicolumn{5}{|l|}{ Exclusive breastfeeding } & \multirow{3}{*}{$\chi^{2}=0.62$} & \multirow{3}{*}{$p>.05$} \\
\hline No & 18 & 36.0 & 21 & 42.0 & & \\
\hline Yes & 32 & 64.0 & 29 & 58.0 & & \\
\hline \multicolumn{5}{|l|}{ Type of nipple } & \multirow{4}{*}{$\chi^{2}=2.8$} & \multirow{4}{*}{$p>.05$} \\
\hline Normal & 29 & 58.0 & 34 & 68.0 & & \\
\hline Flat & 13 & 26.0 & 8 & 16.0 & & \\
\hline Inverted & 8 & 16.0 & 8 & 16.0 & & \\
\hline Medication for pain relief & & & & & & \\
\hline Yes & 32 & 64.0 & 36 & 72.0 & $\chi^{2}=0.98$ & $p>.05$ \\
\hline No & 18 & 36.0 & 14 & 28.0 & & \\
\hline Post natal days & & & & & & \\
\hline 1-3 days & 17 & 34.0 & 15 & 30.0 & & \\
\hline 4-7 days & 27 & 54.0 & 31 & 62.0 & $t=0.46$ & $p>.05$ \\
\hline 8-14 days & 6 & 12.0 & 4 & 8.0 & & \\
\hline Mean $\bar{x} \pm \mathrm{SD}$ & 4.97 & & 4.89 & & & \\
\hline
\end{tabular}

*Significant, $p<.05$

Concerning baseline signs \& symptoms of breast engorge- scored 7-10 points for around half of each group (50.0\% \& ment among two groups (Fenugreek group; group A and 44.0\%), respectively. Also, more than fourth of each group Cabbage group; group B), before application of nursing mea- were suffered from firm and tender breasts $(26.0 \%, 30.0 \%)$ sures. Table $3 \&$ Figure 3 clarify that Numerical rating scale with levels $4 \& 5$ of engorgement, respectively. In addition, 
$50.0 \% \& 60.0 \%$ of each group had 1.1 to $2.9 \mathrm{~cm}$ of redness according to the modified REEDA scale. More than half of both group A and B (50.0\% \& 62.0\%), respectively, were feverish; their temperature were 38.0 and 38.4 for $50.0 \%$ \& $62.0 \%$, respectively. Moreover, LATCH score scored 7-10 points for of each group $(50.0 \% \& 50.0 \%)$, respectively.

Table 3. Comparison of the participants' baseline signs \& symptoms of breast engorgement among the two groups before application of nursing measures

\begin{tabular}{|c|c|c|c|c|c|}
\hline & \multirow{3}{*}{ Variables } & \multicolumn{4}{|c|}{ Study groups } \\
\hline & & \multicolumn{2}{|c|}{ Fenugreek Group $(\mathrm{n}=\mathbf{5 0})$} & \multicolumn{2}{|c|}{ Cabbage Group $(\mathrm{n}=\mathbf{5 0})$} \\
\hline & & $\mathbf{N}$ & $\%$ & $\mathbf{N}$ & $\%$ \\
\hline \multirow{5}{*}{1} & Pain (NRS) & & & & \\
\hline & 0 & 0 & 0.0 & 0 & 0.0 \\
\hline & $1-3$ & 10 & 20.0 & 8 & 16.0 \\
\hline & $4-6$ & 15 & 30.0 & 20 & 40.0 \\
\hline & $7-10$ & 25 & 50.0 & 22 & 44.0 \\
\hline \multirow{4}{*}{2} & Redness (MRS) & & & & \\
\hline & $0-0.5$ & 3 & 6.0 & 5 & 10.0 \\
\hline & $0.6-1.0$ & 17 & 34.0 & 20 & 40.0 \\
\hline & $1.1-2.9$ & 30 & 60.0 & 25 & 50.0 \\
\hline \multirow{7}{*}{3} & Hardness (6-PES) & & & & \\
\hline & 1. Soft and no changes in breast & 4 & 8.0 & 6 & 12.0 \\
\hline & 2. Slight changes in the breast & 8 & 16.0 & 5 & 10.0 \\
\hline & 3. Firm and no tender breast & 6 & 12.0 & 5 & 10.0 \\
\hline & 4. Firm, and beginning tenderness in breast & 13 & 26.0 & 9 & 18.0 \\
\hline & 5. Firm and tender of the breast & 7 & 14.0 & 15 & 30.0 \\
\hline & 6. Very firm and very tender & 12 & 24.0 & 10 & 20.0 \\
\hline \multirow{5}{*}{4} & Temperature & & & & \\
\hline & 37 to $37.4^{\circ} \mathrm{C}$ & 3 & 6.0 & 1 & 2.0 \\
\hline & 37.5 to $37.9^{\circ} \mathrm{C}$ & 12 & 24.0 & 9 & 18.0 \\
\hline & 38 to $38.4^{\circ} \mathrm{C}$ & 25 & 50.0 & 31 & 62.0 \\
\hline & 38.5 to $39.9^{\circ} \mathrm{C}$ & 10 & 20.0 & 9 & 18.8 \\
\hline \multirow{4}{*}{5} & LATCH score & & & & \\
\hline & $0-3$ & 6 & 12.0 & 9 & 18.0 \\
\hline & $4-6$ & 14 & 28.0 & 16 & 32.0 \\
\hline & $7-10$ & 30 & 50.0 & 25 & 50.0 \\
\hline
\end{tabular}

Table 4 clarifies the participants' baseline mean signs \& symptoms of breast engorgement (pain, redness, the hardness of breasts, body temperature, and LATCH score) among the two groups (A \& B) before application of nursing measures. The mean scores of pain (NRS) were $5.25 \pm 3.2 \&$ $6.06 \pm 2.41$; for breast redness were $1.5 \pm 0.67 \& 1.35 \pm$ 0.68 ; for breast hardness were $3.94 \pm 1.38 \& 4.04 \pm 1.65$, for LATCH score were $6.68 \pm 2.6 \& 6.12 \pm 2.69$, and the mean body temperature were $38.22 \pm 0.57 \& 38.23 \pm 0.50$; for Fenugreek group and Cabbage group, respectively. The two studied groups didn't differ significantly in all items of baseline signs \& symptoms of breast engorgement which displayed homogeneity of the two groups.
It was observed from Table 5 that there are statistically significant differences between the two groups of the pain score (Numerical rating scale; NRS), Redness (Modified REEDA Scale; MRS) and hardness of the breast (Six-points engorgement scale; 6-PES), body temperature, and LATCH breastfeeding charting scale for the Fenugreek group (group A) \& Cabbage group (group B), respectively, throughout the follow-up visits; $12 \mathrm{~h}, 24 \mathrm{~h}, 36 \mathrm{~h}$, and 48 hours $(p<.05)$. Also, the table shows that after applying the two different measures for the mothers, there was a significant improvement in breast condition; however, the improvement between Fenugreek group was better and in a shorter time than Cabbage group $(p<.05)$. 


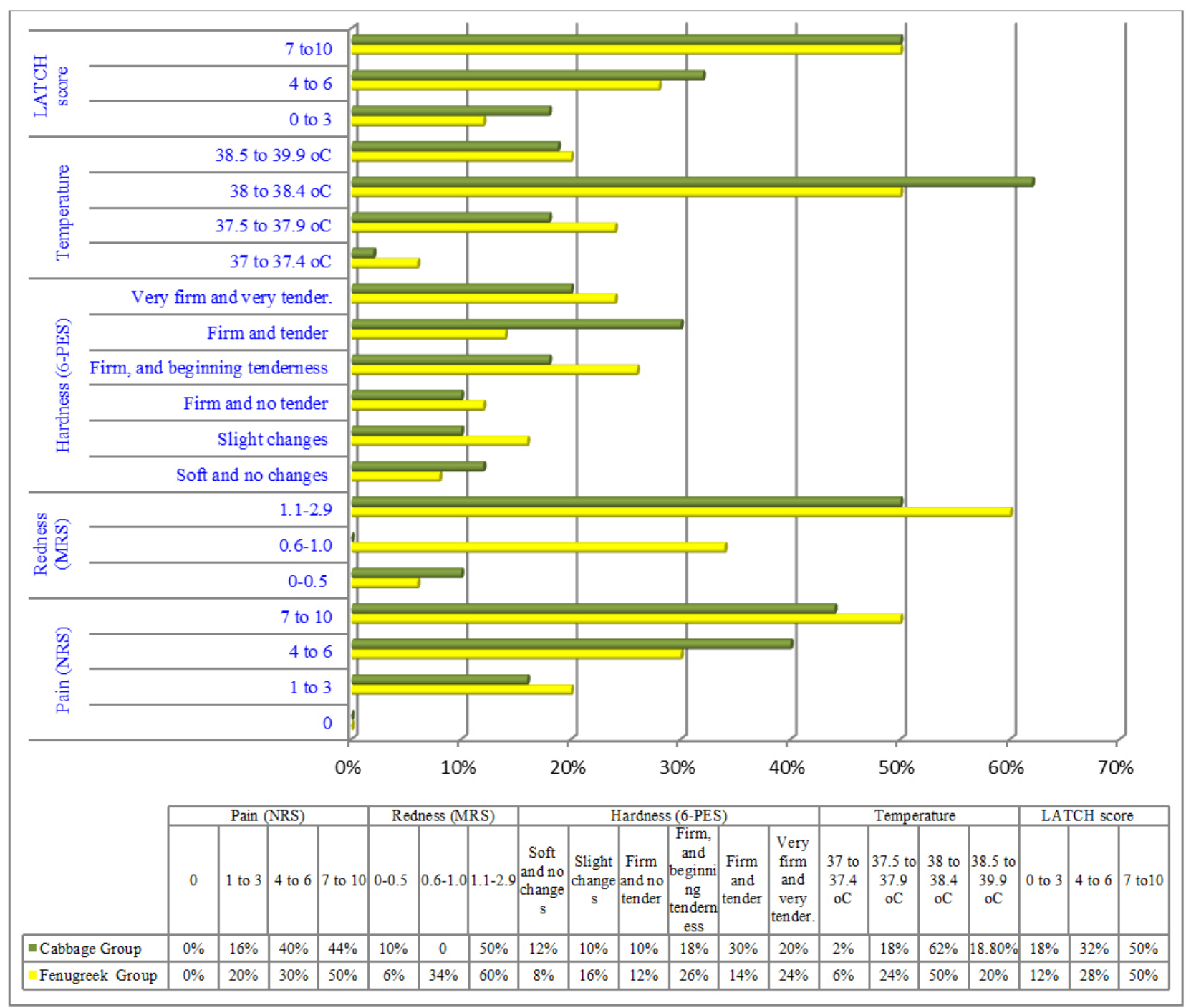

Figure 3. Distribution of the samples according to Baseline measurements signs and symptoms of breast engorgement

Table 4. Distribution of the sample according to Baseline measurements; Mean \pm SD of Pain, Redness, Hardness, Pyrexia, and LATCH score in the Breast Engorgement

\begin{tabular}{lllll}
\hline Baseline measurements (Mean \pm SD) & Fenugreek Group $(\mathbf{n}=\mathbf{5 0})$ & Cabbage Group $(\mathbf{n}=\mathbf{5 0})$ & $\boldsymbol{t}$ Test & $\boldsymbol{p}$-value \\
\hline Pain & $5.25 \pm 3.2$ & $6.06 \pm 2.41$ & 0.18 & $p>.05$ \\
Redness & $1.5 \pm 0.67$ & $1.35 \pm 0.68$ & 1.4 & $p>.05$ \\
Hardness & $3.94 \pm 1.38$ & $4.04 \pm 1.65$ & 0.9 & $p>.05$ \\
Temperature & $38.22 \pm 0.57$ & $38.23 \pm 0.50$ & 0.44 & $p>.05$ \\
LATCH score & $6.68 \pm 2.6$ & $6.12 \pm 2.69$ & 0.28 & $p>.05$ \\
\hline
\end{tabular}

Table 6 \& Figure 4 reveal the complete recovery from (pain, hand, for the cold Cabbage group, the complete recovery redness, hardness, pyrexia \& improving LATCH score) for from hardness, pain, redness, and pyrexia took place within the studied groups throughout follow up visits were at the postpartum 4 visits. For the Fenugreek group, the complete recovery from pain, pyrexia and improving LATCH score took place within 24 hours while redness and hardness completely alleviated 36 hours post-intervention. On the other 48 hours; while improving LATCH score completely alleviated 24 hours post-intervention. Significant differences were observed between two studied groups regarding all items of studied signs and symptoms of breast engorgement. 
Table 5. Comparison between two study grops according to Pain, Redness, Hardness, Pyrexia, and LATCH score in the breast engorgement throughout Follow-up

\begin{tabular}{|c|c|c|c|c|c|c|c|c|}
\hline & \multicolumn{2}{|c|}{ After 12 Hours } & \multicolumn{2}{|c|}{ After 24 Hours } & \multicolumn{2}{|c|}{ After 36 Hours } & \multicolumn{2}{|c|}{ After 48 Hours } \\
\hline & Group A & Group B & Group A & Group B & Group A & Group B & Group A & Group B \\
\hline \multirow{2}{*}{ Pain } & $1.7 \pm 0.8$ & $2.1 \pm 0.8$ & $0.0 \pm 0.0$ & $1.4 \pm 1.1$ & $0.0 \pm 0.0$ & $0.8 \pm 0.4$ & $0.0 \pm 0.0$ & $0.0 \pm 0.0$ \\
\hline & \multicolumn{2}{|c|}{$T=2.4^{*}(p \leq .05)$} & \multicolumn{2}{|c|}{$T=20.0^{*}(p \leq .05)$} & \multicolumn{2}{|c|}{$T=13.3^{*}(p \leq .05)$} & & \\
\hline \multirow{2}{*}{ Redness } & $0.9 \pm 0.8$ & $2.0 \pm 0.8$ & $0.04 \pm 0.3$ & $1.9 \pm 0.9$ & $0.0 \pm 0.0$ & $1.3 \pm 1.2$ & $0.0 \pm 0.0$ & $0.0 \pm 0.0$ \\
\hline & \multicolumn{2}{|c|}{$T=7.1 *(p \leq .05)$} & \multicolumn{2}{|c|}{$T=12.8^{*}(p \leq .05)$} & \multicolumn{2}{|c|}{$T=5.0 *(p \leq .05)$} & & \\
\hline \multirow{2}{*}{ Hardness } & $1.6 \pm 0.7$ & $1.7 \pm 0.8$ & $0.3 \pm 0.6$ & $1.5 \pm 1.2$ & $0.1 \pm 0.1$ & $0.9 \pm 0.8$ & $0.01 \pm 0.1$ & $0.3 \pm 0.5$ \\
\hline & \multicolumn{2}{|c|}{$T=0.8(p \leq .05)$} & \multicolumn{2}{|c|}{$T=6.3 *(p \leq .05)$} & \multicolumn{2}{|c|}{$T=7.5^{*}(p \leq .05)$} & \multicolumn{2}{|c|}{$T=0.54^{*}(p \leq .05)$} \\
\hline \multirow{2}{*}{ Temperature } & $37.7 \pm 0.5$ & $38.1 \pm 0.51$ & $37.2 \pm 0.5$ & $38.0 \pm 0.51$ & $37.0 \pm 0.5$ & $37.5 \pm 0.4$ & $37.0 \pm 0.5$ & $37.2 \pm 0.3$ \\
\hline & \multicolumn{2}{|c|}{$T=2.2 *(p \leq .05)$} & \multicolumn{2}{|c|}{$T=9.2 *(p \leq .05)$} & \multicolumn{2}{|c|}{$T=9.0^{*}(p \leq .05)$} & \multicolumn{2}{|c|}{$T=0.6^{*}(p \leq .05)$} \\
\hline \multirow{2}{*}{$\begin{array}{l}\text { LATCH } \\
\text { score }\end{array}$} & $7.68 \pm 2.9$ & $6.8 \pm 2.7$ & $8.2 \pm 3.3$ & $7.0 \pm 2.9$ & $8.8 \pm 3.1$ & $7.5 \pm 2.5$ & $9.2 \pm 3.0$ & $8.0 \pm 2.6$ \\
\hline & \multicolumn{2}{|c|}{$T=0.22 *(p \leq .05)$} & \multicolumn{2}{|c|}{$T=0.33 *(p \leq .05)$} & \multicolumn{2}{|c|}{$T=0.4 *(p \leq .05)$} & \multicolumn{2}{|c|}{$T=0.51^{*}(p \leq .05)$} \\
\hline
\end{tabular}

*Significant, $p<.05$

Table 6. Comparison between two groups regarding complete recovery from breast engorgement throughout follow-up visits

\begin{tabular}{|c|c|c|c|c|c|c|c|c|c|c|c|c|c|}
\hline \multirow{3}{*}{$\begin{array}{l}\text { Signs \& } \\
\text { Symptoms }\end{array}$} & \multirow{3}{*}{$\begin{array}{l}\text { Sample } \\
\text { Group }\end{array}$} & \multicolumn{10}{|c|}{$\begin{array}{l}\text { Complete Recovery From Signs \& Symptoms Of Breast Engorgement } \\
\text { Throughout Follow Up Visits. }\end{array}$} & \multirow{3}{*}{$\begin{array}{l}\chi^{2} \\
\text { Test }\end{array}$} & \multirow{3}{*}{$p$} \\
\hline & & \multicolumn{2}{|c|}{ pre } & \multicolumn{2}{|c|}{$12 \mathrm{H}$} & \multicolumn{2}{|c|}{$24 \mathrm{H}$} & \multicolumn{2}{|c|}{$36 \mathrm{H}$} & \multicolumn{2}{|c|}{$48 \mathrm{H}$} & & \\
\hline & & $\mathbf{N}$ & $\%$ & $\mathbf{N}$ & $\%$ & $\mathbf{N}$ & $\%$ & $\mathbf{N}$ & $\%$ & $\mathbf{N}$ & $\%$ & & \\
\hline \multirow{2}{*}{ Pain } & Group (A) & 0 & 0 & 25 & 50 & 50 & 100 & 50 & 100 & 50 & 100 & $60.6^{*}$ & $p \leq .05$ \\
\hline & Group (B) & 0 & 0 & 10 & 20 & 19 & 38 & 25 & 50 & 50 & 100 & & \\
\hline \multirow{2}{*}{ Redness } & Group (A) & 0 & 0 & 16 & 32 & 43 & 86 & 50 & 100 & 50 & 100 & $63.2 *$ & $p \leq .05$ \\
\hline & Group (B) & 0 & 0 & 8 & 16 & 29 & 58 & 35 & 70 & 50 & 100 & & \\
\hline \multirow{2}{*}{ Hardness } & Group (A) & 4 & 8 & 28 & 56 & 40 & 80 & 50 & 100 & 50 & 100 & $58.2 *$ & $p \leq .05$ \\
\hline & Group (B) & 6 & 12 & 13 & 26 & 29 & 58 & 42 & 84 & 50 & 100 & & \\
\hline \multirow{2}{*}{ Temperature } & Group (A) & 3 & 6 & 36 & 72 & 50 & 100 & 50 & 100 & 45 & 100 & $28.9 *$ & $p \leq .05$ \\
\hline & Group (B) & 1 & 24.4 & 20 & 40 & 39 & 78 & 43 & 86 & 50 & 100 & & \\
\hline \multirow{2}{*}{ LATCH score } & Group (A) & 0 & 0 & 50 & 100 & 50 & 100 & 50 & 100 & 50 & 100 & $18.7^{*}$ & $p \leq .05$ \\
\hline & Group (B) & 0 & 0 & 36 & 72 & 50 & 100 & 50 & 100 & 50 & 100 & & \\
\hline
\end{tabular}

*Significant, $p<.05$

\section{Discussion}

Breast engorgement is an uncomfortable and painful breast swelling with milk that can make it hard for the baby to properly latch on the mother's breast. ${ }^{[6]}$ It is characterized by intense swelling of the breasts combined with a sudden increase in the amount of milk, vascular congestion and oedema during the 1 st two post-partum weeks. ${ }^{[6,29]}$ If breast engorgement is not treated properly, it can lead to complications such as feeding problems or slow weight gain if the baby is unable to latch on the engorged breast, ${ }^{[28]}$ sore and cracked nipple due to the baby fumbling on/off as he tries to grasp hold of a too firm breast, ${ }^{[30]}$ deep breast pain, ${ }^{[18]}$ Thrush; a fungal infection can be formed on the nipple or within the breast as they live on milk, ${ }^{[31]}$ Plugged ducts, ${ }^{[32]}$
Damage of the milk-producing cells which may, in turn, cause an overall decrease in milk supply, ${ }^{[33]}$ Mastitis, and breast abscess. ${ }^{[34]}$

Because nurses represent the largest group of health-careproviders and are responsible for the quality of care (QOC) given to patients, their perspective on the efficacy of their treatment is very significant. Nurses are one of the main health care providers of postnatal-health-care-services and play important roles in increasing awareness of health issues and dissemination of information. Furthermore, nurses are in a good position to help deliver key preventive and curative health measures to puerperal women. ${ }^{[35-45]}$ Hence, the current study conducted to investigate the impact of nursing intervention on relieve of breast engorgement among puer- 
peral women by apply and compare the effect of two deferent engorged breasts. measures (Fenugreek seed poultice, cold Cabbage leaves) on

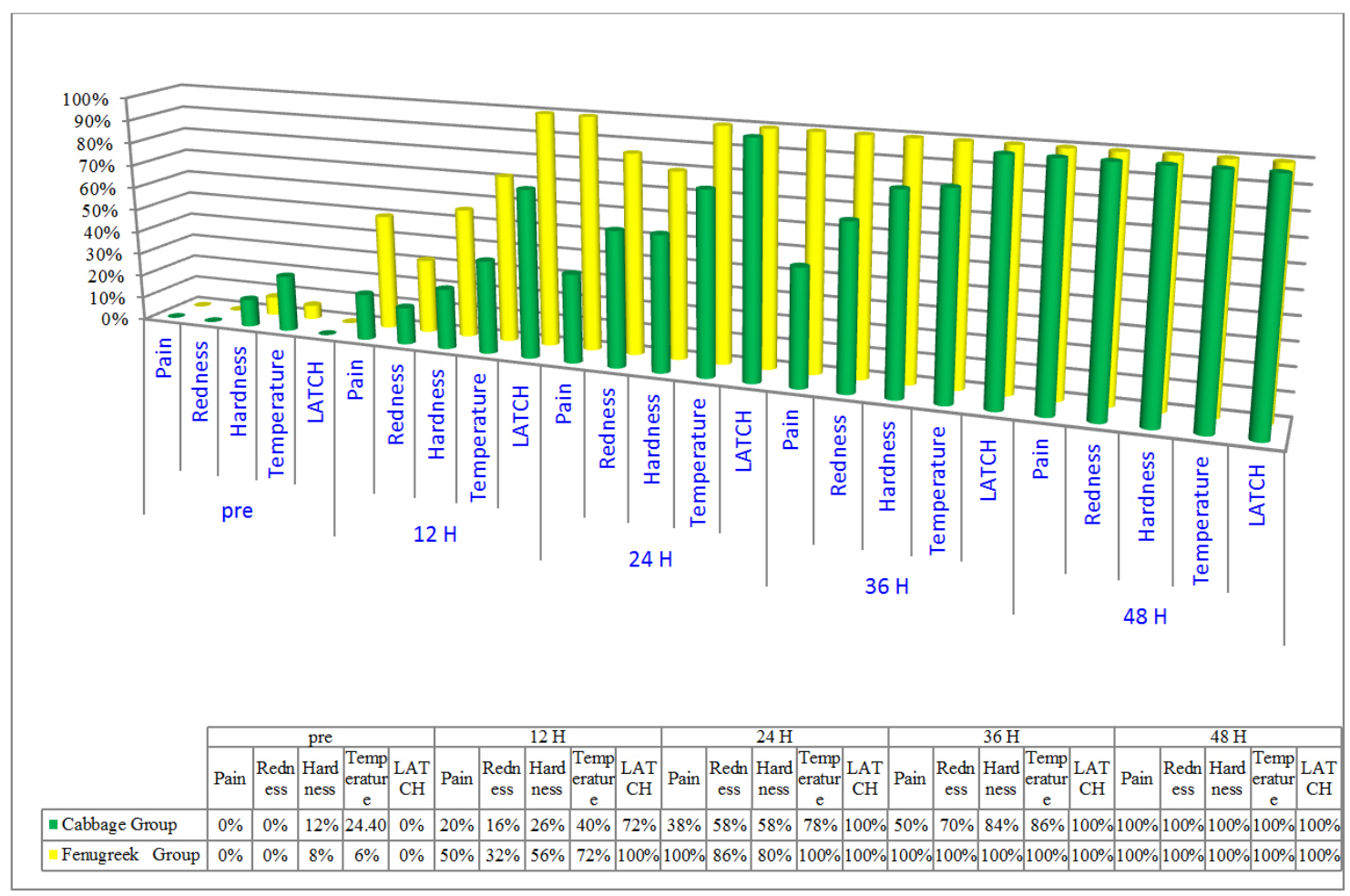

Figure 4. Complete Recovery from Breast Engorgement and Its Signs \& Symptoms throughout Follow up Visits

The results of the current study reveal that the mean age of both studied groups (A \& B) were $24.14 \pm 5.99 \& 23.22 \pm$ 10.49 , respectively. There was no significant difference in the participants' age for the two studied groups (Fenugreek group \& Cabbage group), respectively, which displayed homogeneity of the two groups. This is in line with a study conducted by Eapen \& Fernandes, who studied the efficacy of an information booklet on breast engorgement control measures. They registered the highest percentage of mothers in the grouped age between the ages of 24 and 27. ${ }^{[6]}$

Despite the advantages of breastfeeding, it is not widely practiced due to the pain and discomfort of cesarean section wounds, ${ }^{[46]}$ breast engorgement, and breast pain. ${ }^{[47]} \mathrm{A}$ mother who undergoes CS may neglect breastfeeding and breast-care due to the pain after the surgery, which requires special medical attention. Taking into consideration the obstetrical history, which affects the breastfeeding period, ${ }^{[48]}$ primiparous women, may need an active breast care intervention. It is recommended to initiate breastfeeding within 30 minutes after delivery and before of breast engorgement development. ${ }^{[49]}$

The results of the present study declare that, breast engorgement was more prevalent among women with caesarian sec- tion (C.S) delivery (78.0\% \& $88.0 \%$ ) compared to $22.0 \%$ \& $12.0 \%$ of normal vaginal delivery (NVD), within 4 to 7 days postpartum with the mean $(4.97 \pm 2.77 \& 4.89 \pm$ 2.42). Moreover, a considerable percent $(64.0 \%$ \& $72.0 \%)$ of each group were primiparous for the Fenugreek group $\&$ Cabbage group, respectively. A significant difference between participants' mode of delivery and breast engorgement was observed $(p \leq .05)$. These results may be attributed to women with CS may delay the initiation of breastfeeding till complete recovery from their anesthesia, so, they cannot initiate breast-feeding within 30 minutes after delivery. Furthermore, the immediate postpartum period is problematic for mothers who are delivered by CS due to postoperative pain that may require medical intervention and may impair the mother's ability to breastfeed her baby early and may lead to breast engorgement. This may explain that is why most of the studied women in both groups $(64.0 \% \& 72.0 \%)$, respectively, took Medication for pain relief. The current findings are consistent with many studies stating that women with CS like birth are very vulnerable to the struggles that come 3-4 days after birth including sore/swollen breast. The methods of delivery and parity are factors that affect infant feeding practices. ${ }^{[4,50]}$ 
Concerning baseline (before application of nursing measures) signs \& symptoms of breast engorgement among of Fenugreek group and Cabbage group, respectively; the results of the current study illustrated that redness was the most frequent observable breast-engorgement sign, 1.1 to $9.2 \mathrm{~cm}$ of redness it documented by $60.0 \% \& 50.0 \%$ of the studied groups (A \& B, respectively). Additionally fever (38.0 to 38.4 ) was recorded by $50.0 \% \& 62.0 \%$ of each group, respectively. Numerical rating scale scored 7-10 point for $50.0 \%$ \& $44.0 \%$. Firm, hard, and tender breasts are reported by $26.0 \% \& 30.0 \%$ of the groups with level $4 \& 5$ of engorgement. The analysis of the results declared that redness and fever were the first observable sign and symptom. These results have contradicted the results of El-Saidy \& Aboushady (2016) who found that breast pain and redness of the breast were recorded as the most frequent symptoms of breast engorgement $(88.9 \%$ \& $70.0 \%)$, respectively. Moreover, fever is reported as the least percent (36.7\%) of signs of breast engorgement among their studied women. ${ }^{[6]}$ These differences between the finding of our results and El-Saidy's \& Aboushady's results may be attributed to the heterogeneity of the studied subjects. El-Saidy's \& Aboushady's studied subjects were from El-Manial Maternity hospital, Cairo Governorate, who may have better socioeconomic status and had better availability of health care. Our study subjects were from Upper Egypt (Beni-Suef \& El-Fayoum), Upper Egyptian women may be more tolerable and had a high level of pain-threshold than others.

Regarding participants' mean baseline signs \& symptoms of breast engorgement (pain, redness, the hardness of breasts, body temperature, and LATCH score among the two groups before the application of nursing measures; the Numerical rating scale (NRS), Modified REEDA Scale (MRS), Six-point engorgement scale (6-PES), body temperature, and LATCH breastfeeding charting scale for the Fenugreek group \& Cabbage group, respectively, show no significant differences in all items of signs and symptoms of breast engorgement which displayed homogeneity of the two groups. This finding is consistent with Boi et al. (2017), whose study results indicate that there were no significant differences between the three groups in their baseline outcomes of pain, breast hardness, or body temperature. ${ }^{[5]}$

Several approaches for breast engorgement treatment for puerperal women have been identified as a pro-breastfeeding application of warm compresses, milk expression, cold therapy, breast massage, and oral anti-inflammatory medications. ${ }^{[5,6,51]}$ This is the first study to compare the efficacy of Fenugreek seed poultice and cold Cabbage leaves compresses for breast engorgement.
It is not entirely clear how cabbage leaves will minimize breast engorgement, but there is a high concentration of sulphur in the green cabbage leaf, which is known to reduce swelling/inflammation in all tissues. ${ }^{[52]}$ Cabbage is known to contain rapine, mustard oil, magnesium, oxalates, sulfrheteroside and sinigrin (allylisothiocyanate). Herbalists believe that both antibiotic and anti-irritant properties are present in cabbage. In order to reduce swelling in moderate to severe engorgement, lactation consultants also prescribe compresses made from green cabbage leaves. It is theorized that this natural product combination helps to reduce inflammation/congestion of tissues, allowing the body to reabsorb the fluid accumulated in the breasts. Cabbage has a type of wicking action that helps move trapped fluid. ${ }^{[6,53]}$ Previous studies have confirmed that cabbage compress and breast massage reduce levels of breast engorgement, breast pain, ${ }^{[54,55]}$ and breast temperature ${ }^{[56]}$ and increase breast milk PH. ${ }^{[57]}$ In those studies, breast pain was measured as an index of breast engorgement; however, breast engorgement itself was not measured. In the present study, breast hardness was measured using the Six-point engorgement scale (6-PES) to assess breast engorgement. ${ }^{[4,58]}$

Since fenugreek has versatile properties and several studies have shown its beneficial effects (it contains vitamins such as Niacin, Folic acid, Thiamin, Riboflavin, Vit A, C and minerals as Potassium, Magnesium, Calcium, Zinc, Iron, etc). It has shown its use in diabetes, hypercholesteremia. ${ }^{[9]}$ Fenugreek is a medicinal plant that uses some therapy in disease. The crop contains active ingredients including alkaloids, Flavonoids, hormones, Saponins, etc. It's ancient herbal medicine. It was widely used as traditional food and medicine. It is known that fenugreek has sedative, antiinflammatory, skin softener and lowering effects of fever, and also improves the supply of milk. Recent research has established fenugreek as a beneficial medicinal plant with the ability to cure diseases and as a source to prepare pharmaceutical industry raw materials, such as steroidal hormones. Because fenugreek is a self-pollinated plant, it is possible to use a mutation breeding method to produce mutants with a particular growth habit. It is possible to use irradiation and chemical mutagens to create fenugreek point mutations. ${ }^{[8,9,59]}$

This study compared the effects of Fenugreek seed poultice (FSP) versus cold Cabbage leaves compresses (CCLC) on the breast pain, breast redness, breast hardness, core body temperature, and breast milk LATCH score among puerperal women after birth. The results show that both FSP and CCLC significantly reduced breast pain, redness, tenderness \& firmness, pyrexia, and increase LATCH score as well throughout the follow-up subsequent visits compared to pre-intervention. Significant differences were observed between two differ- 
ent applied interventional measures regarding all mentioned items of signs and symptoms $(p \leq .05)$.

When compare pain intensity among the two studied groups, the results of the present study revealed an observable decreasing in mean pain intensity, in both FSP (group A) and CCLC (group B), throughout the follow-up visits compared to pre-intervention. This indicated that both the interventions (Fenugreek seed poultice $\&$ application of chilled cabbage leaves) were effective in breast-engorgement pain-reduction. El-El-Saidy \& Áboushády (2016) confirmed that on the basis of scientific evidence; cabbage leaves can reduce pain without side effects. So, lactation specialists and midwives recommend cabbage leaves to relieve the pain of engorgement. The literature documented that the cabbage leaves can potentially help in the reduction of hardness/pain of engorged breasts. ${ }^{[6]}$ An uncontrolled pilot study of 30 women with breast engorgement compared pain scores before and after mothers applied cooled cabbage leaves twice daily (15-20 minutes) for three days. Engorgement score after three days was lower than at the start of the study. ${ }^{[60]}$ Non-pharmacological approaches were used in a research hospital to treat breast engorgement mothers. A systematic review was conducted on the effectiveness of application of cabbage leaf on pain/hardness in engorged breast and its effect on the duration of breastfeeding, as well. ${ }^{[18]}$ Cabbage leaves have been found to be potentially helpful in reducing the hardness and pain of the breasts. Previous studies have reported similar effects of using cabbage leaves to reduce pain. ${ }^{[5,20,25,61,62]}$

Moreover, Sinha et al. (2017) and Zhou \& Chan (2012) reported that fenugreek has a sedative, and antibacterial, antiviral action. ${ }^{[9,59]}$ kor et al., (2013) documented that Fenugreek seeds and leaves have a demulcent effect and useful in burning sensation. ${ }^{[8]}$ Before the intervention, however, the mean pain ratings of both groups were equivalent, i.e. both groups experienced similar pain severity with no objectively significant difference between FAP and CCLC groups, statistically significant differences were found throughout the follow-up visits between FAP and CCLC groups ( $p \leq$ .05 ). The efficacy of Fenugreek seed poultice (after 24 hours of intervention) was slightly higher; as the mean pain score after Fenugreek seed poultice application was small i.e. 0.0 \pm 0.0 compared to the application of chilled cabbage leaves i.e. $1.4 \pm 1.1$. This disparity was statistically significant as a result of unpaired t-testing $(p<.05)$.

According to the Six-points engorgement scale (6-PES) used for assessing the hardness of the breast for the Fenugreek group \& Cabbage group, respectively, throughout the followup visits; $12 \mathrm{~h}, 24 \mathrm{~h}, 36 \mathrm{~h}$, and 48 hours. The results of the present study reveal that there was a significant improvement of breast condition for the mothers after the application of the two different measures. A small, nonrandomized study in Korea studied the effect chilled cabbage leaves applied to the engorged breast in primiparous mothers revealed that breast hardness, as measured objectively with a pressure sensor, was lower on days 2, 3 and 4 postpartum in the mothers who received the cabbage leaves, but no difference in subjective pain scores was seen. ${ }^{[63]}$ However, Cochrane review found no statistically significant evidence to link the use of cabbage leaves with a quicker resolution of symptoms of engorgement. ${ }^{[1]}$ The efficacy of cabbage leaves could be due to the presence of enzymes such as rapine and Sinigrin ${ }^{[20]}$ and Sulfrcompound ${ }^{[64]}$ that could have had an anti-inflammatory effect on the breasts, contributing to a decrease in swelling, and hardness. However, the improvement was better and shorter time among the Fenugreek group than the Cabbage group $(p<.05)$.

There was no significant difference in breast hardness before the intervention among the two groups. In the postintervention analysis, the FSP showed the lowest breast hardness level among the two groups. After $12 \mathrm{~h}, 24 \mathrm{~h}, 36$, and $48 \mathrm{~h}$ post-intervention, there was a significant difference between the two groups, and the FSP showed the lowest level. This indicated that the Fenugreek seed poultice application, which was conducted for breast engorgement, was considered to have been effective for relieving breast hardness than chilled cabbage leaves. Based on the results of this study, the Fenugreek seed poultice has softened the breast and reduced the engorgement level. As recommended in the previous study. This was in line with kor et al. (2013) that found and reported that even drinking Fenugreek, the water with which seeds have been soaked and rinsed helps to soften and dissolve, accumulate and harden cellular debris masses. It is claimed that when taken with lemon and honey as it nourishes the body during sickness, the Fenugreek herb helps to reduce breast enlargement. ${ }^{[8]}$

Complete recovery from pain was achieved within only $24 \mathrm{~h}$ and beast hardness was completely relieved within $36 \mathrm{~h}$ after Fenugreek seed poultice application compared to $48 \mathrm{~h}$ after the application of chilled cabbage leaves $(p \leq .05)$. This indicates that Fenugreek seed poultice was more effective in pain, hardness recovery in the engorged breast as mean pain score and Six-point engorgement had more reduction after the Fenugreek seed poultice intervention significantly. This was in accordance with kor et al. (2013) who found and stated that Fenugreek seeds and leaves are anti-inflammatory. The oil in the seeds is used as a skin softener and can alleviate swelling and reduces body fats. ${ }^{[8]}$ Additionally, many researchers documented that fenugreek has a sedative and antibacterial action. ${ }^{[9,59]}$ kor et al. (2013) added that Fenu- 
greek seeds and leaves have a demulcent effect and useful in burning sensation. ${ }^{[8]}$

The results of the present study show the impact of two interventions i.e. application of Fenugreek seed poultice and application of chilled cabbage leaves on the mean core body temperature in managing breast engorgement. The core body temperature in both groups was comparable before starting the intervention. The core body temperature during preintervention phase was higher in group A (Fenugreek seed poultice) and group B (chilled Cabbage leaves) as indicated by the mean core body temperature was $38.22 \pm 0.57 \&$ $38.23 \pm 0.50$, respectively, $(p<.05)$ as per unpaired $t$-test, respectively. The result showed that post-intervention, relative to the pre-intervention engorgement score, the mean core body temperature dropped significantly in both intervention groups. It showed that both approaches were successful in returning to their normal level the mean core body temperature.

The effectiveness of application Fenugreek seed poultice on the engorged breast was little more; as the mean core body temperature compared to the application of chilled cabbage leaves which was comparatively little low i.e. $37.2 \pm 0.5$ as compared to the application of chilled cabbage leaves i.e. $38.0 \pm 0.51$. Complete recovery from pyrexia took place only after $24 \mathrm{~h}$ post-intervention and application Fenugreek seed poultice compered to $48 \mathrm{~h}$ after application chilled cabbage leaves. Hence, this disparity was statistically significant as a result of unpaired $t$-testing $(<.05)$; this meant that both were not equally effective in the treatment of breast engorgement. Fenugreek seed poultice was better in decreasing pyrexia than cold Cabbage. This is in line with many authors that they study the effectiveness of fenugreek on fever and found that; fenugreek is effective for fever control and relief, similar to quinine. Fenugreek herb is known to help relieve fever when taken with lemon and honey as it feeds the body during disease (Home remedies guide). ${ }^{[8]}$

As shown in the results of the present study that mothers who applied the Fenugreek seed poultice had significantly lower redness compared to those in the cold cabbage leaves intervention at all-time points of follow-up. However, both of them get a lower mean score of REEDA scale $(0.9 \pm 0.8$ $\& 2.0 \pm 0.8$ ) from the 1 st point of follow-up (after $12 \mathrm{~h}$ of intervention) compared to the baseline mean scores ( $1.5 \pm$ $0.67 \& 1.35 \pm 0.68$ ). There were significant reductions in redness, per 12 hours increment for both two groups. Pairwise comparisons showed that mothers in the Fenugreek seed poultice had significant reductions in redness $(p \leq .05)$ than cold cabbage leaves. Fenugreek seed poultice performed better recovery than the cold cabbage leaves. Complete re- covery from redness achieved within $36 \mathrm{~h}$ after Fenugreek seed poultice application compered to $48 \mathrm{~h}$ after cold cabbage leaves application. A significant difference was observed between 2 applied measures $(p \leq .05)$.

As presented in the result of the current study, both groups had got better mean LATCH score from the 1st point of intervention $(7.68 \pm 2.9 \& 6.8 \pm 2.7)$ compared to preintervention $(6.68 \pm 2.6 \& 6.12 \pm 2.69)$ for fenugreek and cold cabbage, respectively. However, mothers who received Fenugreek seed poultice intervention had significantly better mean LATCH score compared to those in the cold cabbage leaves intervention at all-time points of follow-up associated with statistically significant differences $(p \leq .05)$. Mothers who applied Fenugreek seed poultice scored significantly higher mean LATCH points at 3 points: 24 hour post-application, 36 hour post-application and 48 hours hour post-application $(8.2 \pm 3.3,8.8 \pm 3.1,9.2 \pm 3.0)$ compared to those in the cold cabbage leaves $(7.0 \pm 2.9,7.5 \pm 2.5$, $8.0 \pm 2.6)$ at the same points associated with statistically significant differences $(p \leq .05)$.

Both Fenugreek seed poultice \& cold cabbage leaves achieved excellent points (7-10) of LATCH score which representing successful breastfeeding after application of interventional measures. However, the Fenugreek seed poultice group got their score before (within 12h after application) and in a shorter time than cold cabbage leaves (within 24 after application). This result is supported by Hale 2012 supports this result; he said Fenugreek appears to be the herb most commonly used to increase the supply of milk. For some mothers, it has been recorded as an excellent galactagogue and has been used for centuries as such. Fenugreek was either used on a short-term basis to improve the production of milk or on a long-term basis to the output and/or yields of pumping. There are no studies that indicate long-term use issues. Some mothers have noticed that the herb can be stopped once the production of milk is increased to a suitable level. Transfer of fenugreek to milk is uncertain, untoward effects are recorded only rarely. ${ }^{[11]}$

Finally, according to the results yielded by the present study, nursing measures seemed to be very useful in achieving a complete recovery of engorgement. The results of the present study reveal the effectiveness of the two methods used to relieve breast engorgement namely Fenugreek seed poultice $\&$ the cold Cabbage leaves; however, Fenugreek seed was more effective and scored better recovery in a shorter time. Furthermore, the study suggests that Fenugreek seed with its properties may be a superiorly effective agent in treating the engorged breast. 


\section{Limitations of the study}

The present study has several limitations, including small sample size, and lack of an equivalent control group for estimating the expectation effects. Moreover, no random sequence generation and allocation concealment increase the risk of bias and may exaggerate the real effects of experimental interventions. On the other hand, although it would have been desirable for a randomized controlled trial by using the double-blinded method, this was not feasible in this study due to the nature of the interventions. The researchers, who conducted the interventions and data collection for postintervention readings of pain, redness, hardness, temperature, and LATCH score for effective breastfeeding, as well as the participants, were not blinded. The participants were aware of the received interventions. Approximately 88.0 percent of the participating mothers (as they delivered normally) discharged from the hospital during the administration of the intervention. Upon discharge and self-reporting the effects, these participants who provided the nursing measures (Fenugreek seed poultice or cold Cabbage leaves) had to administer the intervention by themselves. There was a risk that some participants may not have completely adhered to the study regimens and may not have carefully measured the outcomes. Nevertheless, before their discharge from the hospital, they had agreed to adhere to the treatment plan and showed their ability to measure the outcomes according to the protocol with appropriate guidance.

\section{Conclusion}

It can be concluded on the basis of the results reported by this study that:

For the management of breast engorgement, both Fenugreek seed poultice and cold Cabbage leaves were effective. However, Fenugreek seed was more highly effective where breast engorgement was alleviated in a shorter time than cold Cabbage. Hence, it can reduce pain, redness, pyrexia, and hard- ness, and increase LATCH score in a shorter time than cold Cabbage leaves more effectively at all-time points. There were statistically significant differences between the two interventions applied measures. Hypotheses of the research are accepted.

\section{Rcommendations}

In light of the results of the present study, the following recommendations are suggested:

- Prevention is a key element in reducing breast engorgement potentially among nursing mothers. So, mothers should learn about preventive measures for breast engorgement.

- Early detection and nursing care are important to improve the breastfeeding experience of the infants and to avoid complications of the breast.

- This research area requires more efforts to expand the evidence base on the different approaches to breast engorgement reduction in nursing care.

Further studies should be done in this area as follows:

- Further randomized controlled trials with possible placebo treatment should be carried out to elucidate the non-specific effects of Fenugreek seed poultice and cold Cabbage leaves application.

- Further researches are needed to clarify the magnitude of the breast engorgement problem in Egypt as a whole and compare between rural and urban areas to find out a suitable solution for it.

- Further studies are needed to explore the effectiveness of other traditional (folk) measures on the healing of breast engorgement.

\section{CONFlicts of InTEREST Disclosure}

The authors declare that there is no conflict of interest.

\section{REFERENCES}

[1] Salgaonkar R. Chilled Cabbage Leaves: The Possible Remedy for Breast Engorgement. Int J Nurs Med Invest. 2019; 4(1): 1-3.

[2] Jelovesk FR. Postpartum Health. J Obestet Gyneco Nurs.2006; 92(8): 852 .

[3] Disha RA, Singh A, Suri V. Effect of chilled cabbage leaves vs. hot compression on breast engorgement among post natal mothers admitted in a tertiary care hospital. Nursing and Midwifery Research Journal. 2015; 11(1): 24-32

[4] Lim A, Song J, Hur M, et al. Cabbage compression early breast care on breast engorgement in primiparous women after cesarean birth: a controlled clinical trial. Int J Clin Exp Med. 2010; 8(11): 21335-21342

Published by Sciedu Press
[5] Boi W, Huak Ch, Yi L, et al. Application of cabbage leaves compared to gel packs for mothers with breast engorgement: Randomized controlled trial. International Journal of Nursing Studied. 2017; PII: S0020-7489(17) 30193-1.

[6] El-Saidy T, Aboushady R. Effect of two different nursing care approaches on reduction of breast engorgement among postnatal women. Journal of Nursing Education and Practice. 2016; 6(9): 1828. https://doi.org/10.5430/jnep.v6n9p18

[7] Grossman D. Sore, Cracked Breast Nipple Treatment, The American College of Physicians. Annals of Internal Medicine. 2013; 158(11): 839-840. PMid:23529386 https://doi.org/10.7326/0003-4 819-158-11-201306040-00629

[8] kor N, Didarshetaban M, Pour H. Fenugreek (Trigonella foenum- 
graecum L.) As a Valuable Medicinal Plant. International Journal of Advanced Biological and Biomedical Research. 2013; 1(8): 922-931.

[9] Sinha R, Rauniar G, Panday D, et al. Fenugreek: Pharmacological Actions. World Journal of Pharmacy and Pharmaceutical Sciences. 2016; 5(1): 1481-1489.

[10] Mehrafarin A, Qaderi A, Rezazadeh SH, et al. Bioengineering of Important Secondary Metabolites and Metabolic Pathways in Fenugreek (Trigonella foenumgraecum L.). J. of Medicinal Plants. 2010; 9(35): 1-18.

[11] Hale T. Medications and Mothers' Milk, 10th Edition. Pharmasoft Medical Publishing. 2012: 277-279.

[12] Sim T, Hattingh L, Jillian Sherriff J, et al. The Use, Perceived Effectiveness and Safety of Herbal Galactagogues during Breastfeeding: A Qualitative Study. International Journal of Environmental Research and Public Health. 2015; 12: 11050-11071. PMid:26371019 https://doi.org/10.3390/ijerph120911050

[13] Othman N, Che Lamin R, Othman CH. Exploring Behavior on the Herbal Galactagogue Usage among Malay Lactating Mothers in Malaysia. Procedia - Social and Behavioral Sciences. 2014; 153 199-208. https://doi.org/10.1016/j.sbspro.2014.10.054

[14] Mangesi L, Zakarija-Grkovic I. Treatments for breast engorgement during lactation. Cochrane Database Syst Rev. 2016; 6: CD006946.

[15] Lust KD, Brown JE, Thomas W. Maternal intake of cruciferous veg etables and other foods and colic symptoms in exclusively breast-fed infants. J Am Diet Assoc. 1996; 96: 46-8. https://doi.org/10 .1016/S0002-8223(96)00013-2

[16] Rosier W. Cool Cabbage Compresses. Breastfeeding Rev, 1988; 12 : 28-31.

[17] Fraser D, Cooper M, Fletcher G. Myles Textbook for Midwives. 14th ed. Edinburg: Churchill Livingstone. 2004; 217-9: 625-50: 750-64.

[18] Wong BB, Chan YH, Leow MQ, et al. Application of cabbage leaves compared to gel packs for mothers with breast engorgement: Randomised controlled trial. Int J Nurs Stud. 2017; 76: 92-9. PMid:28941842 https://doi.org/10.1016/j.ijnurstu. 201 7.08 .014

[19] Joy J. A study to evaluate the effectiveness of chilled cabbage leaves application for relief of breast engorgement in volunteered postnatal mothers who are admitted in maternity ward of selected hospital in Belgium. Masters' thesis. KLE University. 2013.

[20] Arora S, Vatsa M, Dadhwal V. A Comparison of Cabbage Leaves vs. Hot and Cold Compresses in the Treatment of Breast Engorgement. Indian J Community Med. 2008; 33(3): 160-162. PMid:19876476 https ://doi.org/10.4103/0970-0218.42053

[21] Haefeli M, Elfering A. Pain assessment. Eur Spine J. 2006; 15: S17S24. PMid: 16320034

[22] Hassan H, Saber N, Sheha E. Comprehension of Dyspareunia and Related Anxiety among Northern Upper Egyptian women: Impact of Nursing Consultation Context Using PLISSIT Model. Nursing \& Care Open Access Journal. 2019; 6(1): 1-19.

[23] Hill PD. Effect of Heat and Cold on the Perineum after Episiotomy/Laceration. Journal of Obstetrical, Gynecological, and Neonatal Nursing. 1989: 124-9. PMid:2709180 https://doi.or $\mathrm{g} / 10.1111 / \mathrm{j} .1552-6909.1989 . \mathrm{tb} 00475 . \mathrm{x}$

[24] Hill PD, Humenick SS. The occurrence of breast engorgement. Journal of Human Lactation. 1994; 10(2): 79-86. PMid:7619260 https://doi.org/10.1177/089033449401000212

[25] Nikodem VC, Danziger D, Gebka N, et al. Do cabbage leaves prevent breast engorgement? A randomised, controlled study. Birth Iss Perinat C Journal. 1993; 20(2): 61-64. PMid:8240608 https: //doi.org/10.1111/j.1523-536X.1993.tb00418.x

[26] Roser D. Breast engorgement and postpartum fever. Obstetrics \& Gynecology. 1966; 27(1): 73-77.
[27] Jensen D, Wallace S, Kelsay P. LATCH: a breastfeeding charting system and documentation tool. Journal of Obstetric, Gynecologic, \& Neonatal Nursing. 1994; 23(1): 27-32. PMid:8176525 https ://doi.org/10.1111/j.1552-6909.1994.tb01847.x

[28] Davidson M, London M, Ladewig P. PLDS, Maternal-Newborn Nursing \& Women's Health across the Lifespan, 2008; 8th ed. USA: Person Prentice Hall.

[29] Ministry of Health - Manat Hauora. Breast engorgement and breast oedema. Health Workforce New Zealand. 2015. Available from: http://www.health.govt.nz/our-work/life-s tages/br eastfeeding/health-practitioners/breast-engorgement-andbreast-oedema. Accessed at 23 October 2015.

[30] Morland Schultz K, Hill P. Prevention of and Therapies for Nipple Pain: A systematic review. Journal of Obstetrical, Gynecological, and Neonatal Nursing. 2005; 34(4): 428-37, 247-75. PMid:16020410 https://doi.org/10.1177/0884217505276056

[31] Agamy H. Breast feeding problems. 2011. Available from: http://www.Fedo.net/MedicalEncyclopedia/womanheal th/womanmarrage/pregnancyanddelivery/problemsofbre astfeeding.htm

[32] Orshan S. Maternity, Newborn, and Women's Health Nursing: Comprehensive care across the lifespan. Philadelphia: Lippincott Williams \& Wilkins Co. 2008; 710-15, 777-93.

[33] Mohrbacher N, Stock J. The Breastfeeding Answer Book. La Leche League. 1997.

[34] Salhan S. Textbook of Obstetrics. New Dlhi: Jaypee brothers Co., 2007; 612-22.

[35] Mohamed W, Hassan H. Educational Program to Enhance Pregnant Women's Knowledge about Dental Care and Periodontitis Outcomes. ARC Journal of Nursing and Healthcare. 2019; 5(3): 23-33. https : //doi .org/10.20431/2455-4324.0503004

[36] Hassan H, Farag D. The impact of polycystic ovary syndrome on women's quality of life: Nursing guidelines for its management. Clinical Nursing Studies. 2019; 7(3): 42-57. https ://doi .org/10.5 430/cns.v7n3p42

[37] Farag D, Hassan H. Maternal Postpartum Sleep disturbance and Fatigue: Factors Influencing. ARC Journal of Nursing and Healthcare. 2019; 5(2): 33-46.

[38] Faheim S, Hassan H, Gamel W. Topical Application of Human Milk versus Alcohol and Povidine-Iodine on Clinical Outcomes of Umbilical Cord in Healthy Newborn: Impact of an Educational Program of Mothers' Knowledge and Practice Regarding Umbilical Cord Care. International Journal of Studies in Nursing. 2019; 4(2): 35-51. https://doi.org/10.20849/ijsn.v4i2.573

[39] Hassan H. Infertility profile, psychological ramifications and reproductive tract infection among infertile women, in northern Upper Egypt. Journal of Nursing Education and Practice. 2016; 6(4): 92108. https : //doi.org/10.5430/jnep.v6n4p92

[40] Abd-Allah N, Nasr E, Hassan H. Impact of a Breast Feeding Educational Program for Mothers Having Pre-Term Infants in General Hospitals in Port Said. International Journal of Novel Research in Healthcare and Nursing. 2017; 4(3): 215-225.

[41] Hassan H, El-Sadek A, Ali L. Effect of Three Different Nursing Interventions on Intestinal Motility and Women's Satisfaction PostCesarean Section Birth. American Journal of Nursing Research. 2019; 7(6): 932-941.

[42] Mohamed W, Hassan H. Effect of Instructional Supportive Guideline for Improving Women's Awareness towards Endometriosis. American Journal of Nursing Research. 2020; 8(1): 38-47.

[43] Gamel W, Genedy A, Hassan H. Impact of Puerperal Sepsis Self-Care Nursing Guideline on Women's Knowledge and Practices. American Journal of Nursing Research. 2020; 8(2): 1-10. 
[44] Farg D, Hassan H. Obstetric Outcomes for Teenage and Adult Pregnancy: A Comparative Study. Nursing \& Care Open Access Journal. 2020; 7(1): in press.

[45] Hassan H, Ahmed W, Mahmoud A. Impact of Tailored Educational Program on Primigravida Anxiety and Knowledge Regarding Minor Discomforts in Upper Egypt. International Journal of Studies in Nursing. 2020; 5(1): 1-16. in press. https ://doi.org/10. 20849 /ijsn.v5i1.698

[46] Yeo JH, Moon GN, Lee SO. Effects of self-breast pumping in primiparous women after cesarean delivery. Korean Journal of Women Health Nursing. 2012; 18: 98-107. https://doi.org/10.4069/ kjwhn.2012.18.2.98

[47] Ahn S, Kim J, Cho J. Effects of breast massage on breast pain, breast-milk sodium, and newborn suckling in early postpartum mothers. J Korean Acad Nurs. 2011; 41: 451-459. PMid:21964220 https://doi.org/10.4040/jkan.2011.41.4.451

[48] Simard I, O'Brien HT, Beaudoin A, et al. Factors influencing the initiation and duration of breastfeeding among low-income women followed by the Canada prenatal nutrition program in 4 regions of quebec. J Hum Lact. 2005; 21: 327-337. PMid:16113021 https: //doi.org/10.1177/0890334405275831

[49] Research society of women's health nursing textbook. Women's health nursing. Paju: Soomoonsa; 2012.

[50] Hawkins T. Preparing Mothers for Breastfeeding after a Cesarean The Educator's Role. 2014. Available from: http://www. scienc eandsensibility.org/preparing-mothers-for-breastf eeding-after-a-cesarean-the-educators-role/

[51] Newman J, Kernerman E. Blocked ducts and mastitis. March 8, 2009. Available from: http://nbci.ca/index.php?option=c om_content\&view=article\&id $=7$ : blocked-ducts-a-mast $i$ tis\&catid $=5$ : inf ormation\&Itemid $=17$

[52] Andrews J. Cabbage for Postpartum Breast Engorgement, 2010. Available from: http://www . babymed.com/Blog-aspxx?454

[53] Davis M. Engorgement: The Cabbage Cure. 2014; Available from: http://www.lactationconsultant.info/cabbagecu re.html Accessed at 24 October 2015.
[54] Arora S, Vatsa M, Dadhwal V. Cabbage leaves vs hot and cold compresses in the treatment of breast engorgement. Nurs J India. 2009; 100: 52-54.

[55] Jung SH. The change of breast engorgement for non-Greast feeding mother after cold cab- bage compress. 2004; Unpublished master's thesis.

[56] Baik MS. The effect on oketani massage to normal breast condition, total protein and total lipid. 2011; master's thesis.

[57] Cho J, Ahn HY, Ahn S, et al. Effects of oketani breast massage on breast pain, thebBreast milk $\mathrm{pH}$ of mothers, and the sucking speed of neonates. Korean Journal of Women Health Nursing. 2012; 18 149-158. https://doi .org/10.4069/kjwhn.2012.18.2.149

[58] Lim HS, Chung KY. Measurement of skin hardness with durometer in normal korean in- dividuals. Korean Journal of Dermatology. 2001; 40: $19-24$.

[59] Zhou J, Chan L. Trigonelline: a plant alkaloid with therapeutic potential for diabetes and central nervous system disease. Curr Med Chem. 2012; 19: 3523-3531. PMid:22680628 https://doi.org/10. 217 4/092986712801323171

[60] Saini P, Saini R. Cabbage leaves and breast engorgement. Indian J Public Health. 2014; 58: 291-292. PMid:25491528 https ://doi. org/10.4103/0019-557X.146309

[61] Roberts KL, Reiter M, Schuster D. A comparison of chilled and room temperature cabbage leaves in treating breast engorgement. J Hum Lact. 1995; 11: 191-4. PMid:7669238 https://doi.org/10.117 7/089033449501100319

[62] Roberts KL. A comparison of chilled cabbage leaves and chilled gel packs in reducing breast engorgement. J Hum Lact. 1995; 11(1): 17-20. PMid:7718101 https://doi .org/10.1177/0890334495 01100118

[63] Lim AR, Song JA, Hur MH, et al. Cabbage compression early breast care on breast engorgement in primiparous women after cesarean birth: A controlled clinical trial. Int J Clin Exp Med. 2015; 8: 21335 42.

[64] Hatfield, G. Encyclopaedia of folk medicine: old world and new world traditions. ABC- CLIO, California. 2004; 59-60. 